${ }^{1}$ PDM Dental College \& Research Institute, Bahādurgarh, India.

2 Jamia Millia Islamia, Faculty of Dentistry, Delhi, India.
Corresponding author: Abhishek Mehta

Jamia Millia Islamia, Faculty of Dentistry, Delhi, India

e-mail:amehta@jmi.ac.in

Editor: Dr Altair A. Del Bel Cury

Received: March 03, 2021

Accepted: June 06, 2021

\section{Knowledge and practices of recording and maintaining patients 'dental records among private dental practitioners of Delhi, India}

\author{
Gurkiran Kaur ${ }^{1}$, Abhishek Mehta ${ }^{2, \star}$ (D), Aastha Sahani ${ }^{1}$, \\ Shradha Malik ${ }^{1}$
}

Proper recording and keeping dental records are an important part of any dental practice. It helps in improving patient care, has medico-legal importance and play significant role in human identification during mass disasters or criminal offences. Aim: To assess the knowledge and practices of recording and maintaining patients 'records among private dental practitioners of Delhi, India. Methods: Data for this cross-sectional study was collected from 160 dentists of Delhi using a self-administered questionnaire. The face and content validity as well as reliability of questionnaire was tested before the final data collection. A single trained examiner collected all the necessary information via personal visits or google forms. Chi-square test was applied to check the statistically significant difference between the dichotomous independent variables with respect to study participants' responses to the questionnaire. Results: The mean age of the study participants was 34.5 (SD 7.2) years.Digital method of recording patient's data and $\mathrm{x}$-ray storage was more prevalent than manual method among the study participants. Slightly more than $40 \%$ of the dentists were keeping patient's records safe for a period of 6 to 10 years. Younger dentists with lesser years of practice were more explicit in recording and correcting patient records. Conclusion: Results of this study shows that private dental practitioners of Delhi are aware of medico-legal importance of dental records. Most of them were recording important findings and history of their patients. Dentists must be educated in two aspects namely correct method of recording and the ideal duration of storing their patients' dental records.

Keywords: Dental records. Dentists. Forensic dentistry. 


\section{Introduction}

The dental record is an official document that has all the diagnostic information (odontogram, radiographs and casts), clinical notes, treatment performed and patient-related communications that occur in the dental office, including instructions for home care and consent to treatment ${ }^{1}$. Recording the patient -related data in an accurate, comprehensive and efficient manner is an important part of clinical practice. Dental records are useful in cases of malpractice suits, insurance claims and in the field of forensic dentistry. A complete dental record of the patient is a valuable commodity in human identification in cases of bite assaults, child abuse or age disagreements as in child marriages and child labour or criminal proceedings ${ }^{2,3}$. These records can aid in the identification of a dead or missing person, criminal investigations and in cases of mass disasters. Numerous instances are on record wherein dental records have been used to identify the victims of mass disasters such as 2004 tsunami and in criminal investigations as in the 2012 Nirbhaya rape case in Delhi ${ }^{4,5}$. In a systematic review of 20 mass disasters, in 17 of them the use of forensic odontology for identification of the victims was found in about $14.70 \%$ cases. In Kentucky air crash $100 \%$ of the identification was done by dental remains, $76 \%$ in Newark air crash and $71.42 \%$ in Nepal air crash ${ }^{6}$.

Dental records can play an important role in identification of a dead body which has been grossly decomposed and is difficult to identify visually. This is due to the capability of dental tissues to withstand high temperature, humidity and pressure. But the critical feature of dental identification lies in being able to obtain accurate ante-mortem records that can be matched with the post-mortem dental findings $s^{7,8}$. Developed countries have a well-established system of maintaining patients' dental record. This is unlike what we commonly find in developing countries like India wherein in spite of extensive dental treatment a person's complete dental chart is usually not available. This acts as a hindrance in cases relating to mass disasters or crime involving decomposed unidentified remains as there is no ante-mortem data to match the available post-mortem findings.

Studies conducted in India have shown the lack of awareness and practice of dental record maintenance especially by private dental practitioners ${ }^{9-12}$. These practices make the dentist prone to being guilty of negligence under consumer protection law and also reduces the wider role for the dentists in the field of forensic science. Delhi is the capital of India and lies in a zone-4 of earthquake prone seismic areas ${ }^{13}$. It is important that every dental health care professional in Delhi should maintain proper records that can be obtained in case of mass disasters so as to supplement forensic medicine teams for victim identification. Therefore, this study was planned with the objective to assess the knowledge and practices of dentists working in private clinics across Delhi regarding the writing and maintenance of patients' dental records.

\section{Materials and Methods}

\section{Study design, Sampling Frame and Sample size}

This was a questionnaire-based cross-sectional study conducted among private dental practitioners in Delhi state. Based on the similar studies conducted in India, 
it was observed that a sample size of around hundred-fifty dentists is appropriate for present study ${ }^{9,11}$. As there is no directory of registered dentists in Delhi, we contacted local Indian Dental Association branches for the list of their member dentists. We shortlisted 180 dentists via convenience sampling method from this list, in case few dentists refused to participate.

\section{Participants and Ethical clearance}

Dentist practicing within Delhi state limits and were willing to participate after signing written consent form were eligible for this study. Before starting the study a research proposal was submitted to the ethical research committee of the Prabhu Dayal Memorial dental college and research institute and ethical clearance was obtained on 27-04-2019 (letter no. PDM/IEC/02/2019).

\section{Setting and data collection}

The student investigator (AS) collected the data under the supervision of the guide (GK). The selected dentists were contacted telephonically and explained the objectives of conducting this study. Those willing to participate were requested for appointment and the student investigator personally went to their clinic to get the questionnaire filled. Written informed consent was obtained before participants started to respond to the questionnaire. Dentists were also given the option of filling online questionnaire through google form. Twenty five dentists opted for online submission. Data collection was done within two months (July and August 2019).

\section{Questionnaire performa}

A self-designed questionnaire comprising of 24 close-ended questions was used to collect the data from the participating dentists. The questionnaire was divided into four blocks, namely, baseline characteristics of study participants, importance and method of recording case history and dental findings, technical considerations of record keeping and final block of question focused on radiographic records and their preservation. The questionnaire was sent to five experts in the field of forensic odontology. Their inputs and suggestions were used to make changes and finalize the questionnaire (face and content validity). Most of the suggestions were on changing the way questions are framed so that study participants are able to understand them. The reliability was tested by repeating the questionnaire to ten previously participating dentists. The kappa value was 0.8 , hence found to be good.

\section{Statistical Analysis}

SPSS (statistical package for social sciences) version21 was utilized for statistical analysis of the recorded data. One-sample binomial test was applied to check statistical differences in frequency distribution of independent variables such as gender and highest qualification. Statistical difference between the responses of the study participants according to dichotomous groups such as age and years of practices was assessed using chi-square test. $P$ value was set at less than 0.05 . 


\section{Results}

Among the 180 dentists contacted for this study, only 160 gave consent and completed the questionnaire. Hence response rate was $88.8 \%$. The main reason for refusing to participate in the study was lack of time to complete the questionnaire. There were significantly more males than females in the final sample. Also, significantly more participating dentists had completed only bachelor's degree (66.3\%) when compared to those (33.7\%) who had done post-graduation as well (one sample binomial test, $p<0.05$ ). Therefore, we didn't do further comparison of study participants based on these two variables. We divided study participants into approximately equal size dichotomous groups based on age i.e upto 32 and above 32 years and number of years of practice i.e upto 8 and above 8 years for further comparative analysis. These groups were created in such a way that approximately equal number of dentists are there in each group. Most of the dentists agreed that not maintaining dental records is a medical negligence $(n=156,97.5 \%)$. Slightly more than half $(n=93,58.1 \%)$ of the participating dentists felt dental records must be kept safe for medico legal purpose. Forty-seven (29.4\%) dentists felt good record keeping helps in providing better services to their patients (table 1).

Table 1. Baseline characteristics of the study participants

\begin{tabular}{|c|c|c|c|}
\hline Characteristics & $\mathrm{N}$ & $\%$ & $P$ value \\
\hline Overall & 160 & 100 & \\
\hline \multicolumn{4}{|l|}{ Age group } \\
\hline$<=32$ years & 76 & 47.5 & \\
\hline$>32$ years & 84 & 52.5 & \\
\hline \multicolumn{4}{|l|}{ Gender* } \\
\hline Male & 93 & 58.1 & 0.04 \\
\hline Female & 67 & 48.9 & \\
\hline \multicolumn{4}{|l|}{ Highest qualification** } \\
\hline BDS & 106 & 66.3 & 0.0001 \\
\hline MDS & 54 & 33.7 & \\
\hline \multicolumn{4}{|l|}{ Number of years of practice } \\
\hline$<=8$ years & 88 & 55.0 & \\
\hline$>8$ years & 72 & 45.0 & \\
\hline \multicolumn{4}{|c|}{ Do you know not keeping dental records is a medical negligence? } \\
\hline Yes & 156 & 97.5 & \\
\hline No & 04 & 2.5 & \\
\hline \multicolumn{4}{|l|}{ Most important reason for record keeping? } \\
\hline medico legal purpose & 93 & 58.1 & \\
\hline better patient service & 47 & 29.4 & \\
\hline helps in transferring patient to other dentist & 02 & 1.3 & \\
\hline all of the above & 18 & 11.3 & \\
\hline
\end{tabular}

*significant difference between the groups $p<0.05$, one sample binomial test

** Highly significant difference, $p<0.0001$, one sample binomial test 
More dentists were recording case history performa digitally $(n=74,46.2 \%)$ when compared to writing on a printed form $(n=44,27.5 \%)$ or on a blank page $(n=42.26 .3 \%)$, although, the difference between them was not statistically significant. Almost all the dentists ( $n=157,98.1 \%$ ) were asking and recording medical history from the patients visiting their clinic. Only two-third of the dentists were recording number of teeth present $(N=101,63.1 \%)$, teeth with restorations $(N=107,66.9 \%)$ or caries $(n=139,86.9 \%)$ or any abnormalities in dentition or jaws $(\mathrm{N}=107,66.9 \%)$. Around $3 / 4^{\text {th }}$ of the participating dentists ( $n=123,76.9 \%$ ) were recording the type of prosthesis their patient was wearing (table 2).

Table 2. Study participants' response on practice of recording case history and dental findings

\begin{tabular}{|c|c|c|c|c|c|c|c|}
\hline Questions & $\begin{array}{c}\text { Age } \\
\text { upto } \\
32 \text { years }\end{array}$ & $\begin{array}{c}\text { Age } \\
\text { above } \\
32 \text { years }\end{array}$ & $\begin{array}{c}P \\
\text { value }\end{array}$ & $\begin{array}{c}\text { Years of } \\
\text { practice } \\
\text { upto } \\
8 \text { years }\end{array}$ & $\begin{array}{c}\text { Years of } \\
\text { practice } \\
\text { above } \\
8 \text { years }\end{array}$ & $\begin{array}{c}P \\
\text { value }\end{array}$ & $\begin{array}{c}\text { Overall } \\
\text { N (\%) }\end{array}$ \\
\hline
\end{tabular}

Do you start a record file for all

new patients?

\begin{tabular}{|c|c|c|c|c|c|c|c|}
\hline Yes & $73(96.1)$ & $79(94)$ & 0.41 & $83(94.3)$ & $69(95.8)$ & 0.47 & 152(95) \\
\hline No & $03(1.9)$ & 05(3.1) & & $05(5.7)$ & 03(1.9) & & $08(5)$ \\
\hline \multicolumn{8}{|l|}{ How do you record case history? } \\
\hline manually on a printed forms & $17(22.4)$ & $27(32.1)$ & & $22(25)$ & $22(30.6)$ & & $44(27.5)$ \\
\hline manually on a blank page & $22(28.9)$ & $20(23.8)$ & 0.37 & $22(25)$ & $20(27.8)$ & 0.56 & $42(26.3)$ \\
\hline digital & $37(48.7)$ & $37(44)$ & & $44(50)$ & $30(41.7)$ & & $74(46.2)$ \\
\hline
\end{tabular}

Do you record medical history

of the patients?

\begin{tabular}{|c|c|c|c|c|c|c|c|}
\hline Yes & 73(96.1) & $84(100)$ & 0.10 & $85(96.6)$ & 72(100) & 0.25 & 157(98.1) \\
\hline No & $3(3.9)$ & 0 & & $3(3.4)$ & 0 & & $3(1.9)$ \\
\hline
\end{tabular}

Do you document teeth which are present and sound?

\begin{tabular}{|c|c|c|c|c|c|c|c|}
\hline Yes & $52(68.4)$ & 49(58.3) & 0.19 & $60(68.2)$ & 41(56.9) & 0.18 & 101(63.1) \\
\hline No & $24(31.6)$ & $35(41.7)$ & & $28(31.8)$ & $31(43.1)$ & & $59(36.9)$ \\
\hline \multicolumn{8}{|c|}{ Do you record all carious teeth? } \\
\hline Yes & $68(89.5)$ & $71(84.5)$ & 0.48 & $79(89.8)$ & $60(83.3)$ & 0.24 & 139(86.9) \\
\hline No & $08(10.5)$ & $13(15.5)$ & & $09(10.2)$ & $12(16.7)$ & & 21(13.1) \\
\hline
\end{tabular}

Do you record teeth with restorations?

\begin{tabular}{|c|c|c|c|c|c|c|c|}
\hline Yes & $56(73.7)$ & $51(60.7)^{*}$ & 0.09 & $64(72.7)$ & $43(59.7)^{\star}$ & 0.09 & $107(66.9)$ \\
\hline No & $20(26.3)$ & $33(39.3)$ & & $24(27.3)$ & $29(40.3)$ & & $53(33.1)$ \\
\hline
\end{tabular}

Do you record type

of prosthesis?

\begin{tabular}{|c|c|c|c|c|c|c|c|}
\hline Yes & $63(82.9)$ & $60(71.4)^{\star}$ & 0.09 & $75(85.2)$ & $48(66.7)^{\star}$ & 0.008 & $123(76.9)$ \\
\hline No & 13(17.1) & $24(28.6)$ & & $13(14.8)$ & 24(33.3) & & $37(23.1)$ \\
\hline
\end{tabular}

Do you note any additional abnormalities in the dentition and jaws?

\begin{tabular}{|c|c|c|c|c|c|c|c|}
\hline Yes & $60(78.9)$ & $47(56)^{\star \star}$ & 0.002 & $73(83)$ & $34(47.2) \star * *$ & 0.0001 & $107(66.9)$ \\
\hline No & $16(21.1)$ & $37(44)$ & & $15(17)$ & $38(52.8)$ & & $53(33.1)$ \\
\hline
\end{tabular}


Continuation

\begin{tabular}{|c|c|c|c|c|c|c|c|}
\hline \multicolumn{8}{|c|}{$\begin{array}{l}\text { Do you mention prescribed } \\
\text { medication in the record file? }\end{array}$} \\
\hline Yes & $57(75)$ & $49(58.3)^{*}$ & 0.03 & $65(73.9)$ & $41(56.9)^{*}$ & 0.02 & $106(66.3)$ \\
\hline No & 19(25) & $35(41.7)$ & & $23(26.1)$ & $31(43.1)$ & & $54(33.8)$ \\
\hline \multicolumn{8}{|c|}{$\begin{array}{l}\text { Do you keep record of every } \\
\text { treatment done? }\end{array}$} \\
\hline Yes & 73(96.1) & $72(85.7)^{*}$ & 0.02 & $85(96.6)$ & $60(83.3)^{*}$ & 0.004 & 145(90.6) \\
\hline No & $03(3.9)$ & $12(14.3)$ & & 03(3.4) & $12(16.7)$ & & $15(9.4)$ \\
\hline
\end{tabular}

*statistically significant difference, $p<0.05$; chi-square test

** Highly significant difference, $p<0.0001$

Significantly more number of younger dentists (up to 32 years) and those with less than 8 years of practice were recording teeth with restorations $(n=107,66.9 \%)$ or any abnormalities in dentition or jaws, presence of any prosthesis as compared to their elder counterpart. They were also mentioning the name of medication prescribed by them and treatment done on the particular appointment in significantly higher proportion as compared to the corresponding group. Most of the dentists were keeping a record of every treatment done ( $n=145,90.6 \%)$ on their patients with younger dentists recording this finding in higher frequency as compared to older ones (table 2).

Slightly more than half ( $n=85,53.1 \%)$ of the participating dentists were obtaining written informed consent from all of their patients whereas $43.1 \%(n=69)$ were obtaining it for selected cases only. When asked regarding method of making a correction in dental record sheet, $71.3 \%(n=114)$ dentists were using a single line to cross out and very few reported they cut the written matter in such a way that nobody can read it $(n=21,13.1 \%)$. Slightly more than half $(n=86,53.8 \%)$ of the participating dentists were writing an explanation for the corrections they do in dental record sheet, this practice was followed in significantly higher frequency by younger group of dentists. There was variability in response to question related to duration of retaining patient records, $44.4 \%(n=71)$ of the dentists were retaining from 6 to 10 years but $43.2 \%(n=69)$ were retaining patients records for less than one year. Sixty percent $(\mathrm{N}=96)$ were preserving patient record file with themselves, whereas $23.8 \%(n=38)$ were giving it to the patient and $16.3 \%(n=26)$ were just handing over a copy of the records sheet. Dentists in the age group of upto 32 years and those with less than 8 years of practice reported in statistically significantly higher numbers that they are recording date and time of their patient's every visit to the dental office (table 3 ).

Table 3. Practice of study participants regarding technical considerations of record keeping

\begin{tabular}{|c|c|c|c|c|c|c|c|}
\hline Questions & $\begin{array}{c}\text { Age } \\
\text { upto } \\
32 \text { years }\end{array}$ & $\begin{array}{c}\text { Age } \\
\text { above } \\
32 \text { years }\end{array}$ & $\begin{array}{c}P \\
\text { value }\end{array}$ & $\begin{array}{c}\text { Years of } \\
\text { practice } \\
\text { upto } \\
8 \text { years }\end{array}$ & $\begin{array}{c}\text { Years of } \\
\text { practice } \\
\text { above } \\
8 \text { years }\end{array}$ & $\begin{array}{c}P \\
\text { value }\end{array}$ & $\begin{array}{l}\text { Overall } \\
\mathrm{N}(\%)\end{array}$ \\
\hline \multicolumn{8}{|c|}{$\begin{array}{l}\text { Do you record date and time of } \\
\text { patient's every visit to the clinic? }\end{array}$} \\
\hline Yes & $70(92.1)$ & $68(81)^{\star}$ & 0.06 & $82(93.2)$ & $56(77.8)^{*}$ & 0.006 & 138(86.3) \\
\hline No & $06(7.9)$ & 16(19) & & $06(6.8)$ & $16(22.2)$ & & $22(13.8)$ \\
\hline
\end{tabular}


Continuation

\begin{tabular}{|c|c|c|c|c|c|c|c|}
\hline \multicolumn{8}{|c|}{$\begin{array}{l}\text { Do you obtain written informed } \\
\text { consent from your patients? }\end{array}$} \\
\hline Yes for all patients & $43(56.6)$ & $42(50)$ & & $53(60.2)$ & $32(44.4) *$ & & $85(53.1)$ \\
\hline $\begin{array}{l}\text { Only for few selected } \\
\text { patients }\end{array}$ & $29(38.2)$ & $40(47.6)$ & 0.36 & $31(35.2)$ & $38(52.8)$ & 0.08 & $69(43.1)$ \\
\hline Only for child patients & $04(5.3)$ & $02(2.4)$ & & $04(4.5)$ & $02(2.8)$ & & $06(3.8)$ \\
\hline \multicolumn{8}{|c|}{$\begin{array}{l}\text { What do you use for writing } \\
\text { records? }\end{array}$} \\
\hline Ball or ink pen & $63(82.9)$ & $66(78.6)$ & & $67(76.1)$ & $62(86.1)$ & & $129(80.6)$ \\
\hline Pencil & 0 & $01(1.2)$ & 0.54 & $1(1.1)$ & 0 & 0.22 & $01(0.6)$ \\
\hline Phone or tab & $13(17.1)$ & $17(20.2)$ & & $20(22.7)$ & $10(13.9)$ & & $30(18.8)$ \\
\hline
\end{tabular}

Do you maintain a

chronological order of the recorded data?

\begin{tabular}{|c|c|c|c|c|c|c|c|}
\hline Yes & $54(71.1)$ & $57(67.9)$ & 0.39 & $66(75)$ & $45(62.5)^{\star}$ & 0.06 & $111(69.4)$ \\
\hline No & $22(28.9)$ & $27(32.1)$ & & $22(25)$ & $27(37.5)$ & & 49(30.6) \\
\hline \multicolumn{8}{|l|}{$\begin{array}{l}\text { How do you make a correction } \\
\text { in dental records sheet? }\end{array}$} \\
\hline Single line cross out & $57(75)$ & $57(35.6)$ & & $64(72.7)$ & $50(69.4)$ & & 114(71.3) \\
\hline Double line cross out & $03(3.9)$ & 07(8.3) & 0.63 & 03(3.4) & $07(4.4)$ & 0.36 & $10(6.3)$ \\
\hline $\begin{array}{l}\text { cut in a way that nobody can } \\
\text { read it }\end{array}$ & 10(13.2) & $11(13.1)$ & & 12(13.6) & $09(5.6)$ & & 21(13.1) \\
\hline correction fluid & $06(7.9)$ & $08(9.5)$ & & $09(10.2)$ & $05(6.9)$ & & $14(8.8)$ \\
\hline with eraser & 0 & $01(1.2)$ & & 0 & $01(1.4)$ & & $01(0.6)$ \\
\hline
\end{tabular}

Do you preserve all

correspondence related to

the patients?

\begin{tabular}{|c|c|c|c|c|c|c|c|}
\hline Yes & $53(69.7)$ & $41(48.8)^{\star}$ & 0.006 & $64(72.7)$ & $30(41.7)^{\star \star}$ & 0.0001 & $94(58.8)$ \\
\hline No & $23(30.3)$ & $43(51.2)$ & & $24(27.3)$ & $42(58.3)$ & & $66(41.3)$ \\
\hline
\end{tabular}

Do you write any explanations

for corrections in the dental record?

\begin{tabular}{|c|c|c|c|c|c|c|c|}
\hline Yes & $47(61.8)$ & $39(46.4)^{*}$ & 0.03 & $57(64.8)$ & $29(40.3)^{*}$ & 0.002 & $86(53.8)$ \\
\hline No & $29(38.2)$ & $45(53.6)$ & & $31(35.2)$ & 43(59.7) & & $74(46.2)$ \\
\hline \multicolumn{8}{|l|}{$\begin{array}{l}\text { Duration of retaining the dental } \\
\text { records }\end{array}$} \\
\hline Less than one year & $36(47.4)$ & $33(39.2)$ & & $40(44.9)$ & 29(39.5) & & $69(43.2)$ \\
\hline 1 to 5 years & 08(10.5) & 10(11.9) & 0.59 & 05(5.7) & 13(18.1) & 0.18 & 18(11.3) \\
\hline 6 to 10 years & $31(40.8)$ & $40(47.6)$ & & $42(47.7)$ & $29(40.3)$ & & $71(44.4)$ \\
\hline More than 10 years & $01(0.6)$ & $01(0.6)$ & & $01(0.6)$ & $01(0.6)$ & & $02(1.3)$ \\
\hline \multicolumn{8}{|l|}{$\begin{array}{l}\text { What do you do with the patient } \\
\text { record file after treatment? }\end{array}$} \\
\hline preserve the file with myself & $43(56.6)$ & $53(63.1)$ & & $54(61.4)$ & 42(58.3) & & $96(60)$ \\
\hline give file to the patient & $21(27.6)$ & $17(20.2)$ & 0.54 & $22(25)$ & $16(22)$ & 0.60 & $38(23.8)$ \\
\hline $\begin{array}{l}\text { handover a copy of record to } \\
\text { the patient }\end{array}$ & 12(15.8) & 14(16.7) & & 12(13.6) & 14(19.4) & & $26(16.3)$ \\
\hline
\end{tabular}

*Statistically significant difference, $p<0.05$; chi-square test 
On the questions related to radiographs, $70 \%(n=112)$ of the dentists reported that they were taking digital $x$-ray exclusively. Slightly more than half ( $n=84,52.5 \%$ ) of them were retaining digital copy of the patient's radiograph, whereas some were retaining hard copy $(n=19,11.9 \%)$ or keeping one copy with them and providing other to patient ( $n=27,16.9 \%)$. Most of the dentists in the study participating reported that they mention radiographic findings in dental record sheet $(n=131,81.9 \%)$. No significant difference was observed for the responses to these questions based on age group or years of practice (table 4).

Table 4. Responses of participants to questions related to radiographic records and their preservation

\begin{tabular}{lcc}
\hline Questions & Frequency & Percentage \\
\hline Which type of radiographs do you take in your clinic? & & \\
\hline Conventional & 25 & 15.6 \\
\hline Digital & 112 & 70 \\
\hline Both & 23 & 14.4 \\
\hline Do you mention radiographic findings in case sheet? & & \\
\hline Yes & 131 & 81.9 \\
\hline No & 29 & 18.1 \\
\hline What do you do with patient radiograph after treatment? & & 11.9 \\
\hline retain $x$ ray as a hard copy & 19 & 52.5 \\
\hline retain $x$ ray as a soft copy & 84 & 17.5 \\
\hline handover $x$ ray to the patient & 28 & 16.9 \\
\hline one copy with you and other to patient & 27 & 1.3 \\
\hline do not retain $x$ ray & 02 & \\
\hline
\end{tabular}

\section{Discussion}

As dental patients are becoming more aware of their rights and protecting consumer laws, there has been an increase in identification of cases of dental malpractice. During any legal procedure a written document or the past radiograph of the patient has more weightage than verbal statement of the patient or the health care professional, hence, it has become crucial for dental professionals to maintain a comprehensive patient record. Apart from medico-legal aspect, dental records are useful in forensic dentistry, as a mean of communication with other dentist, patient's follow-up visit, providing information to third - party insurer and research purposes ${ }^{3}$. This questionnaire survey tried to probe on the awareness and practices of recording and maintenance of dental records by private dental practitioners of Delhi.

Keeping the dental records of the patients in a safe, retrievable manner for a specified period is an important part of clinical dental care. Various countries and associations have specified the minimum period of the maintenance of patient's records. This duration usually ranges from 6 to 10 years ${ }^{1,14}$. In India, physicians are required to store their patient records for 3 years and clinical trials participants' data upto 5 years ${ }^{15}$. But unfortunately, the laws in India are not practiced as strictly as they should be. 
In the present study, only $44.4 \%(n=71)$ participating dentists were maintaining dental records for 6 to 10 years and $43.2 \%(n=69)$ for less than a year. In comparison, studies done in other states of India had reported a skewed picture of record maintenance where of the total sample only $7 \%^{16}, 18 \%{ }^{12}, 38 \%{ }^{10}, 43 \%{ }^{17}$ to $50 \%^{11}$ dentists were maintaining dental records for the desired period. There are debates as to whom the dental records belong to, dentist or patient, therefore it is safe that both keep them safely. Patient can be provided a copy of their original dental record sheet. Around 16\% of the dentists in our study were following this practice whereas majority of them $(n=96$, $60 \%)$ were keeping it with them only.

Recording the date and time of appointment of the patient has a medico-legal significance. It can be used as an evidence for time and location of the person. In our survey, 86.3\% $(n=138)$ dentists were recording date and time of their patient's every visit to their clinic. These numbers are similar to those reported in a study done in Sudan ${ }^{18}$. An encouraging finding of our survey was significantly more number of younger dentists and those with fewer years of practice were recording date and time of their patient's every visit as compared to their comparative groups. Another aspect of recording proper method of correcting the errors. If the dentist wishes to do any correction in the patient's dental record it should be a single cross cut with a line. Use of correction ink is not recommended nor should it be cut in a way that nobody can read it. Around $30 \%$ of the participating dentists were not following the correct method of error correction in our study. These mistakes can go against the dental professional in the court of law during malpractice litigations.

Dental record keeping should not be a time-consuming exercise otherwise it will discourage the practicing dentists to follow its correct and systematic method. Specifically designed computer software can save the time and energy of the dentist in record-keeping and should be encouraged in dental practice. In our study, only $46.2 \%$ $(n=74)$ of the participating dentists reported that they are keeping dental record digitally. This figure is higher than reported among dentists of Mangalore (2\%) ${ }^{12}$, Pune $(11 \%)^{11}$, Madhya Pradesh $(24 \%)^{17}$ and Rajasthan $(26 \%)^{10}$. Dentists must be made aware of these soft wares.

Record keeping of additional investigations advised during the course of diagnosis and treatment is equally important. Most common of these investigations is the radiographs. Dentists must keep record of the radiograph/s taken and mention its findings in the patient record file. More than $80 \%$ of the participating dentists $(n=130,81.2 \%)$ were safe-keeping patient's radiograph either as hard or digital copy with themselves. This figure is higher than reported in dentists of Mangalore (59\%) ${ }^{12}$, Punjab and Uttar Pradesh (47\%) ${ }^{9}$, and Pune $(77 \%)^{11}$.

Asking and recording medical history is an important and mandatory aspect of case history. Failure to record proper medical history can have medico-legal consequences in case of any medical emergencies arising after dental treatment or medications prescribed by the dentist. Majority of the participating dentists in our study had reported to record medical history $(n=157,98.1 \%)$ in patient case sheet. Similar studies conducted in other parts of India had reported less figures ranging from $22 \%$, $31 \%^{12}, 38 \%{ }^{10}$ to $44.6 \%^{11}$. A study in Sudan reported that $57.1 \%$ of the surveyed dentists were recording medical history ${ }^{18}$. 
Few limitations of this study are, firstly, as the sampling frame for this study is limited to private dental practitioners of Delhi state therefore, these results don't reflect the knowledge and practices of Indian dentists on dental record writing and keeping. Second, as this is a self -reporting study it is prone to recall bias. Third, there may be issue of selection bias as dentists are selected from a list of members of an association hence we may have missed interviewing non-member dentists.

In conclusion, overall the participating dentists had fair knowledge of importance of patients ' record but still some of them were making mistakes while writing and maintaining them safely for recommended period of time. Lack of knowledge and poor implementation of good practices were common among dentists of higher age group and more years of dental practice. This could be due to absence of regular reinforcement for good dental practices among Indian dental fraternity. We suggest a two prong strategy to overcome this shortcoming by means of regulatory approach in form of stricter laws and second, an educational approach for correct information dissemination aimed at increasing awareness of dentists towards standard rules of recording and maintaining dental records. Future research on this subject is required with a larger sample size and more questions pertaining to forensic dentistry.

\section{References}

1. American Dental Association. Council on Dental Practice. Division of Legal Affairs. Dental records. ADA; 2010 [cited 2021 Feb 25]. Available from: https://www.aapd.org/globalassets/media/safetytoolkit/dental-records-ada.pdf.

2. Avon SL. Forensic odontology: the roles and responsibilities of the dentist. J Can Dent Assoc. 2004 Jul-Aug;70(7):453-8.

3. Gooneratne I. Dental records: medico-legal and clinical significance. Sri Lanka Dent J. 2015;45(2):63-8.

4. Morgan OW, Sribanditmongkol P, Perera C, Sulasmi Y, Van Alphen D, Sondorp E. Mass fatality management following the South Asian tsunami disaster: case studies in Thailand, Indonesia, and Sri Lanka. PLoS Med. 2006 Jun;3(6):e195. doi: 10.1371/journal.pmed.0030195.

5. Kattiman BF. Nirbhaya case: Dharwad college helped with forensic analysis. The Times of India. 2013 Sep 13 [cited 2021 Feb 24]. Available from: https://timesofindia.indiatimes.com/city/hubballi/ nirbhaya-case-dharwad-college-helped-with-forensic-analysis/articleshow/22528229.cms.

6. Prajapati G, Sarode SC, Sarode GS, Shelke P, Awan KH, Patil S. Role of forensic odontology in the identification of victims of major mass disasters across the world: A systematic review. PLoS One. 2018 Jun;13(6):e0199791. doi: 10.1371/journal.pone.0199791.

7. Chandra Shekar BR, Reddy CV. Role of dentist in person identification. Indian J Dent Res. 2009 Jul-Sep;20(3):356-60. doi: 10.4103/0970-9290.57377.

8. Devadiga A. What's the deal with dental records for practicing dentists? Importance in general and forensic dentistry. J Forensic Dent Sci. 2014 Jan;6(1):9-15. doi: 10.4103/0975-1475.127764.

9. Gupta A, Mishra G, Bhutani H, Hoshing C, Bhalla A. Forensic revolution need maintenance of dental records of patients by the dentists: A descriptive study. J Int Soc Prev Community Dent. 2016 JulAug;6(4):316-20. doi: 10.4103/2231-0762.186799.

10. Astekar M, Saawarn S, Ramesh G, Saawarn N. Maintaining dental records: Are we ready for forensic needs? J Forensic Dent Sci. 2011 Jul;3(2):52-7. doi: 10.4103/0975-1475.92143. 
11. Sarode GS, Sarode SC, Choudhary S, Patil S, Anand R, Vyas H. Dental records of forensic odontological importance: Maintenance pattern among dental practitioners of Pune city. J Forensic Dent Sci. 2017 Jan-Apr;9(1):48. doi: 10.4103/jfo.jfds_1_16.

12. Wadhwani S, Shetty P, Sreelatha SV. Maintenance of antemortem dental records in private dental clinics: Knowledge, attitude, and practice among the practitioners of Mangalore and surrounding areas. J Forensic Dent Sci. 2017 May-Aug;9(2):78-82. doi: 10.4103/jfo.jfds_64_15.

13. Wikipedia. Earthquake zones of India [cited 2019 Jul 18]. Availible from: https://en.wikipedia.org/ wiki/Earthquake_zones_of_India.

14. College of Dental Surgeons of British Columbia. Dental records management. Vancouver: CLDS; 1996 [cited 2020 May 3]. Available from: https://www.academia.edu/6307817/Dental_Records_Mgt.

15. Indian Council of Medical Research. National ethical guidelines for biomedical and health research involving human participants. New Delhi: ICMR; 2017 [cited 2020 Sep 16]. Available from: https://main.icmr.nic.in/sites/default/files/guidelines/ICMR_Ethical_Guidelines_2017.pdf.

16. Preethi S, Einstein A, Sivapathasundharam B. Awareness of forensic odontology among dental practitioners in Chennai: A knowledge, attitude, practice study. J Forensic Dent Sci. 2011 Jul;3(2):63-6. doi: 10.4103/0975-1475.92145.

17. Tomar U, Airen B, Sarkar PA, Singh H, Bishen KA. A vigilance alert for forensic odontology: Preservation and maintenance of dental records in Central India. Indian J Dent Sci. 2020;12(1):16-20. doi: 10.4103/IJDS.IJDS_61_19.

18. Waleed P, Baba F, Alsulami S, Tarakji B. Improtance of dental records in foresic dental identification. Acta Inform Med. 2015;23(1):49-52. doi: 10.5455/aim.2015.23.49-52. 